\title{
ON THE ADVANCED PVD COATINGS FOR THREADING IN AUSTENITIC STEEL
}

\author{
PISKA, M[iroslav] \& POLZER, A[les]
}

\begin{abstract}
An effective threading of austenitic steel with HSS taps protected by CrAlN, TiCN and TiN PVD coatings was tested. The chrom-nickel austenitic non-stabilized steel (X5CrNi 18-10), was threaded with the HSS-E M6-6H Narex Zdanice taps at the cutting speed $v c=10 \mathrm{~m} / \mathrm{min}$, with outer cooling fluid Cimperial HD 801-03 - 10\%, a flood cooling intensity and 60 bars in press. A CNC machining centre MCV 1210 with a built-in dynamometer KISTLER 9272 were used for the machining technology and measurements. The results showed an effective cutting with a tool life of 40-45 holes and acceptable quality of threads for HSSE with the CrAlN coating. Key words: PVD, austenite, threading, tap, cooling
\end{abstract}

\section{INTRODUCTION}

Taps are cutting tools used to create screw threads, mainly of a short lentgh and small diameters. The technological process of cutting threads using a tap is called "tapping" and can be performed with several different cutters - bottoming, plug and taper taps, covering all cutting actions from roughing to chasing. Stainless steels possess some properties, such as low thermalconductivity and high ductility that make them be excellent construction materials but also should be classified as materials of poor machinability that exhibit a lot of difficulties during cutting e.g. strain hardening, production of long chips, built-up-edge (BUE) and other difficulties when a high quality of surface is demanded (Slany et al, 2011, Piska, 2012).

Our previous industrial research has shown that the important reasons causing premature tap breakages are as follows:

- a wear of tap that cannot be easily quantified or predicted safely in workshop conditions,

- a use of tap with improper tap geometry for a particular application,

- a use of non-standard or inferior quality taps,

- non-convenient cutting speed,

- a mismatch of machine feed and tap or inappropriete hole diameter can cause the tap to break in tension or compression,

- a misalignment of tap and holes axes (tapping does not follow the pre-tap hole)

- a clogging with chips due to poor cutting performance and poor chip evacuation,

- a poor cooling or lubricating (a use of improper cutting fluid or not poweful cooling flow).

Today, the new technologies in tapping are focused on mainly:
- new materials made with powder metallurgy (high speed steels and cemented carbides),

- $\quad$ safe tap holding during threading and the run-in and run-out passes,

- new cooling fluids with high-pressure additives applied with inner cooling through canals,

- wear-resistant hard protective coating (Veprek 20034),

- tapping attachments for pitch and feed compensations (tensile, thrust or both).

The special tool holders are required to minimize the threats of tap breakage during tapping and they can be classified as conventional tool holders and special CNC tool holders.

The hard coatings for cutting tools can be divided by production methods and physical properties. PVD processes seem to be superior and more versatile in production compared to CVD processes (Prochazka 2004, Rosén et al, 2006-7), especially for precise shapes where taps rank. The choice of the substrate or protective coating in the specific machining operation can have serious impact on machining productivity and economy. The coating protects the tool against abrasion, adhesion, diffusion, formation of comb cracks and other wear due to the high strength of their covalent inter-atomic bond, small bond distance, high coordination number and its Vickers hardness HV of 40-60 and >70 GPa (Veprek et al 2003, Prochazka et al, 2004). The widely used PVD hard coatings are TiN (the long-term standard from the late $\left.70^{\prime} \mathrm{s}\right), \mathrm{Ti}(\mathrm{C}, \mathrm{N}),(\mathrm{Ti}, \mathrm{Al}) \mathrm{N},(\mathrm{Al}, \mathrm{Ti}) \mathrm{N},(\mathrm{Ti}, \mathrm{Al}, \mathrm{Si}) \mathrm{N}$, $(\mathrm{Al}, \mathrm{Cr}) \mathrm{N}$ and $\mathrm{CrN}$ are applicable not only to the carbides, but also on HSS tools. In many cases the deposition of the cutting tool with a hard coating increases cutting performance and tool life in the range of $100-1,200 \%$. The reasons for the outstanding features of the $(\mathrm{Ti}, \mathrm{Al})$ based coatings can be defined as for (Cselle, Holubar, 2003):

- $\quad$ very high hardness (25-38 GPa), with relatively low residual compression stresses 3-5 GPa),

- $\quad$ high hot hardness, resulting in low hardness lost (30$40 \%$ ) up to temperatures of $800^{\circ} \mathrm{C}$,

- high oxidation resistance (the same rate for $\mathrm{Ti}(\mathrm{C}, \mathrm{N})$ at $800^{\circ} \mathrm{C}$ as for $\mathrm{TiN}$ at $400^{\circ} \mathrm{C}$ ),

- low heat conductivity (up to $30 \%$ lower relative heat indention coefficient than for TiN).

The research of the substrates or the highly protective coating in specific machining operations can have serious impact on machining productivity and economy. 
The coating industry is enormously innovative today. There is a lot of research and solutions even to improve these outstanding features of coatings, especially the (Al, Ti)N for:

- a suitable combination of ARC and sputtering,

- an effective filtering of ARC-droplets,

- an optimization of process parameters like ARCcurrent, BIAS-voltage, N2-pressure, etc.,

- $\quad$ an optimization of the crystalline structure to avoid the columnar structure and corrosion,

- a deposition of the multilayers to increase coating toughness and thickness.

A new progress in this field is more focused on (Cr,Al)N coating (Zhao et al, 2012), but first experimental works started earlier (Humar, 2004) and Harish et al, 2006). However, all these research works confirm high demands on purity of used materials for coating, special conditions of cutting surface preparations and advanced coating technologies to reach optimal surface integrity for individual technologies and effective use in industrial practise (Veprek et al 2011, Piska et al, 2009).

\section{THEORY OF TAPPING}

The main loading of a tap is made by the chip cross section and specific cutting force (Shaw, 2005). However, the chip cross-section depends on the depth of a tap penetration into a material - Fig. 1, 2.

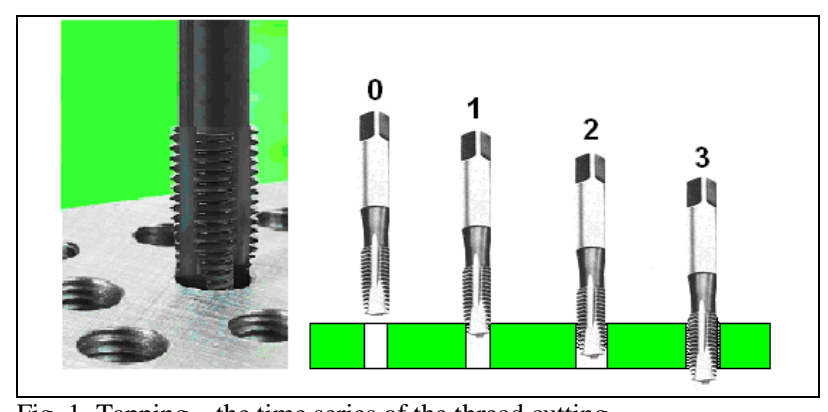

Fig. 1. Tapping - the time series of the thread cutting

For the individual intervals of tapping (depth of tap plunging) the chip cross-section can be expressed as:

a) $1 \in<0,1 \mathrm{k})$

$$
A_{D l}=A_{D \max } \cdot\left(2 \cdot l z \cdot \operatorname{tg} K_{r} / v-l z^{2} \cdot \operatorname{tg}^{2} K_{r} / v^{2}\right)
$$

b) $1 \in<1 \mathrm{k}, \mathrm{L}>$;

$$
\begin{gathered}
A_{D 2}=A_{D \max }=s . v / 2 \\
\text { c) } l \in(\mathrm{L}, \mathrm{L}+\mathrm{lk}> \\
A_{D 3}=A_{D \max } \cdot\left(1-\left(2 \cdot \mathrm{lz} \cdot \operatorname{tg} K_{r} / v-l z^{2} \cdot \operatorname{tg}^{2} K_{r} / v^{2}\right)\right)
\end{gathered}
$$

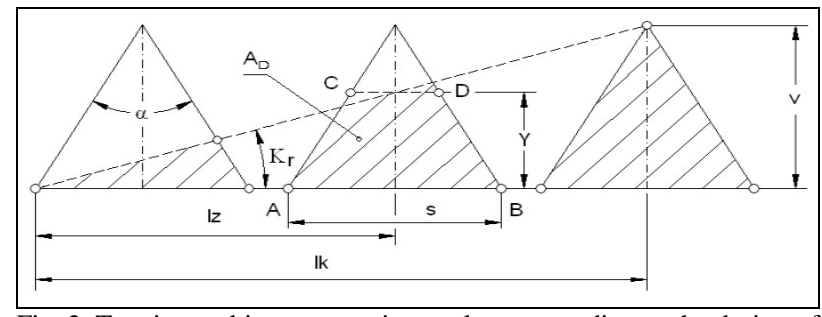

Fig. 2. Tapping - chip cross section analyses according to the design of the threading too
The most important period of cutting for the statistical evaluation is the period ad b), when the tap is totally cut-in and cutting tool is loaded in maximum. For a sharp tap that value is nearly stabilized, close to normal distribution and can be assessed by mean and standard deviation. For a worn tap the value is growing rapidly due to passive and active force loading.

Cutting force $F_{c}[\mathrm{~N}]$, cutting moment $M c[\mathrm{Nm}]$ a cutting power $P c[\mathrm{~kW}]$ are defined by equations (4-6), where $D m$ is the middle diameter of a thread in [mm], $\mathrm{n}$ number of rotations $\left[\mathrm{min}^{-1}\right]$ ) and $k c$ is a specific cutting force [MPa] (ISO 3002-4):

$$
\begin{gathered}
F_{c}=k_{c} \cdot A_{D} . \\
M_{c}=F_{c} \cdot D_{m}, / 2000, \\
P_{c}=M_{c} \cdot n / 9.55 .
\end{gathered}
$$

The calculations are more complicated when passive forces and wear are inluded in the calculations and time development.

\section{EXPERIMENTAL WORKS}

The material of the workpiece - Tab.1 - was the austenitic stainless steel, CSN 10088-1 1.4301 (X5CrNi 18-10), with dimensional and shape deviation tolerances according to EN 9445. The blank sheets 100x8x6000 mm were cut into $200 \mathrm{~mm}$ in length. The workpieces were mounted to a wise which was fixed with screws on the top of the dynamometer KISTLER 9272, fully controlled with a computer. The dynamometer set was placed into the new CNC machining centre MCV 1210 (ZPS TAJMAC, share company, Zlin) controlled with the Sinumerik 840D - Fig. 3. Kistler dynamometer 9272, charge amplifiers 9011 and the Dynoware program for force and torque analyses of the sample loading were used. The sampling rate $3 \mathrm{kHz}$, low-pass filter and the long time constant were set for all data acquisition. A special CNC programme was written for automatic control of the taping operations with a use of the canned cycles. The following technological sequence of tools was set:

- short helical carbide center drill ø6.4 mm, Guhring, Art. Nr. 736, HSK - A63 D17356) for the center hole drilling,

- solid carbide drills $\varnothing 5.00 \mathrm{~mm}$, thermogrip Bilz - HSK A63 ø8 $\left(\mathrm{v}_{\mathrm{c}}=60 \mathrm{~m} / \mathrm{min}, \mathrm{f}=0.1 \mathrm{~mm}\right)-$ drilling the pilot hole (4 pieces),

- countersink 90\%ø30 mm, DIN 335, Guhring, Art. Nr. 327 tool holder - thermogrip Bilz - HSK A63 ø20,

- HSS-E tap M6-6H, producer Narex Zdánice, un-coated and PVD coated with monolayer TiN, AlTiN and CrAlN coating, each sort with 3 samples, the same thickness of coating 2.5-3.2 $\mu \mathrm{m})$.

These three hard coatings were applied with the PVD LARC $®$-technology (LAteral Rotating ARC-Cathodes) of the company Platit (Switzerland). The cathodes were built in very close to each other here and a highly ionized 
plasma, strong magnetic field and fast motion of the ARC-track were achieved. Both water-cooled cathodes were in permanent rotation. The magnetic field was generated by coils and permanent magnets were controlled vertically and radially.

\begin{tabular}{|c|c|c|c|c|c|c|}
\hline \multicolumn{7}{|c|}{ Chemical composition (weight \%) } \\
\hline $\mathrm{C}$ & \multicolumn{2}{|c|}{$\mathrm{Si}$} & $\mathrm{Mn}$ & \multicolumn{2}{|c|}{$\mathrm{P}$} & $\mathrm{Ni}$ \\
\hline$\leq 0.08$ & \multicolumn{2}{|c|}{$\leq 0.10$} & $\leq 2.0$ & \multicolumn{2}{|c|}{$\leq 0.045 \%$} & $\leq 8.0-10.5$ \\
\hline $\mathrm{Cr}$ & \multicolumn{2}{|c|}{$\mathrm{S}$} & $\overline{\mathrm{Fe}}$ & & & \\
\hline $\begin{array}{l}18.00- \\
20.00\end{array}$ & \multicolumn{2}{|c|}{$\leq 0.030 \%$} & Rest & & & \\
\hline \multicolumn{7}{|c|}{ Mechanical properties } \\
\hline \multicolumn{3}{|c|}{$\begin{array}{c}\text { Yield point } R_{e} \\
\text { [MPa] }\end{array}$} & \multicolumn{2}{|c|}{$\begin{array}{c}\text { Tensile strength } \\
\mathrm{R}_{\mathrm{m}}[\mathrm{MPa}]\end{array}$} & \multicolumn{2}{|c|}{$\begin{array}{l}\text { Young modullus } \\
{[\mathrm{GPa}]}\end{array}$} \\
\hline \multicolumn{3}{|c|}{$240-250$} & \multicolumn{2}{|c|}{$520-640$} & & 190 \\
\hline
\end{tabular}

Tab. 1 Composition and properties of the tested material

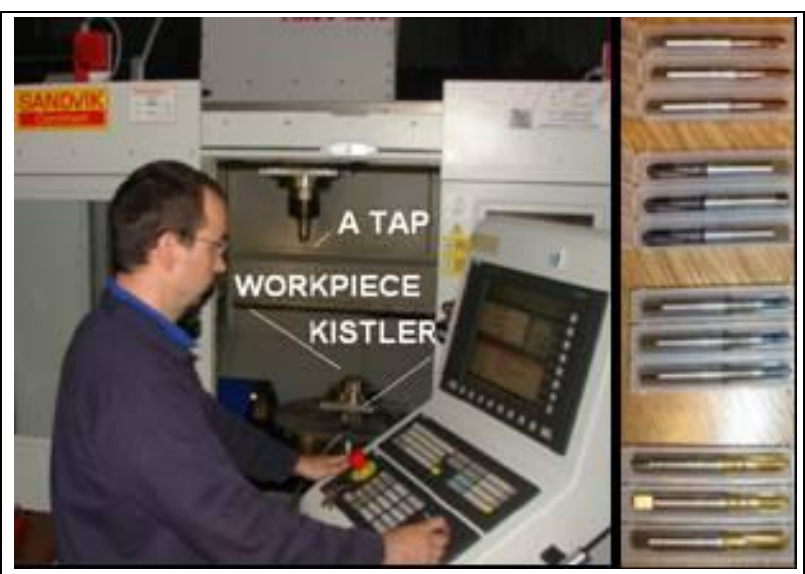

Fig. 3 Experimental set-up, tested series of taps

These tapping cutters were gripped in compensation adapteur Emuge Franken KSN Synchro IKZ with the push-pull loading compensation. The Cimperial HD 80103 (10\% concentration, 60 bars in pressure, flood intensity $50 \mathrm{l} / \mathrm{min}$ ) and outer system of cooling with an emulsion reservoir of 1,200 litres for the machining were used. The temperature of the cooling fluid as measured during all machining and it was changing in the range of $20-22^{\circ} \mathrm{C}$. The cutting speed for tapping was kept the same $-\mathrm{v}_{\mathrm{c}}=10 \mathrm{~m} / \mathrm{min}$ and the thread gauge M6-6H was used for the first dimensional evaluations.

An overview of the first cutting passes based on torque measurements for all taps can be seen in Fig. 4. The statistically assessed results confirmed a short, quasi-static period (when the whole cross-section of the thread was made) with mean specific cutting force $1942 \pm 435 \mathrm{MPa}$ for all cutting tools and coatings.

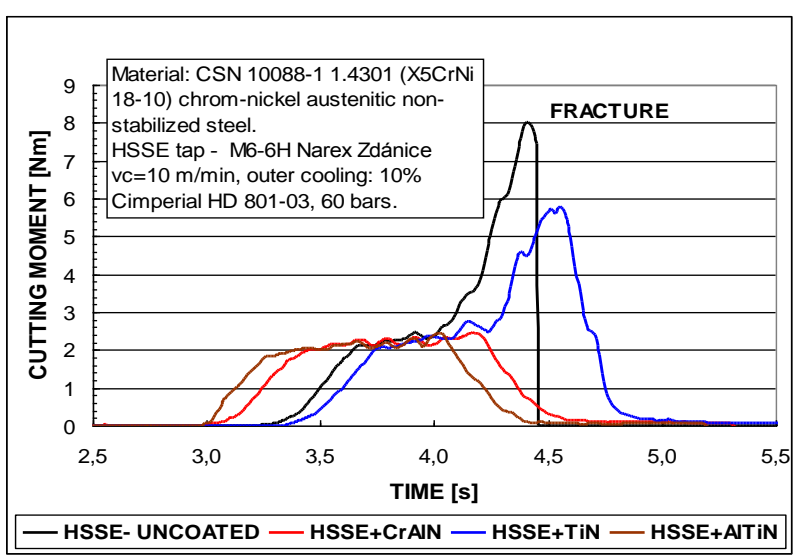

Fig.4 Time series of torques for first cutting operations for all sorts of tools

However, the cutting performance for uncoated HSSE tap was extremaly poor and one tool was broken even in the first hole.

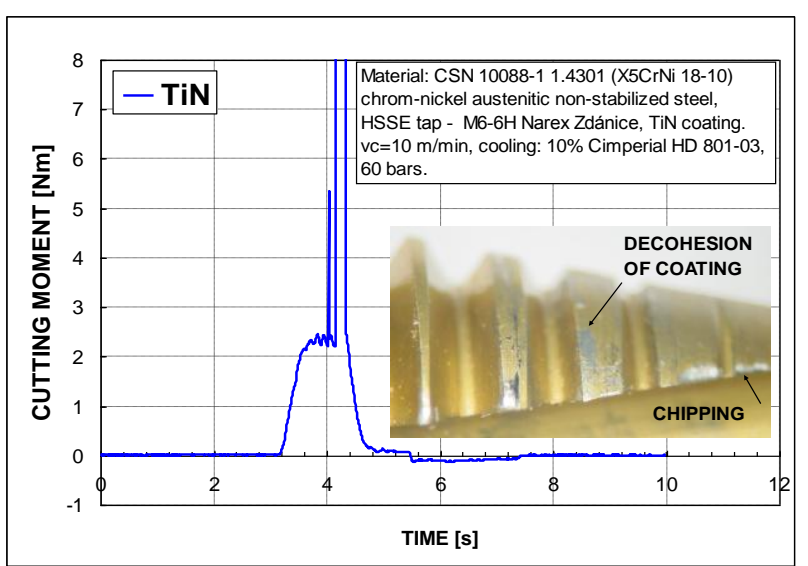

Fig.5. A time series of torque for HSSE+TiN, confirming a rapid flank wear of the tap

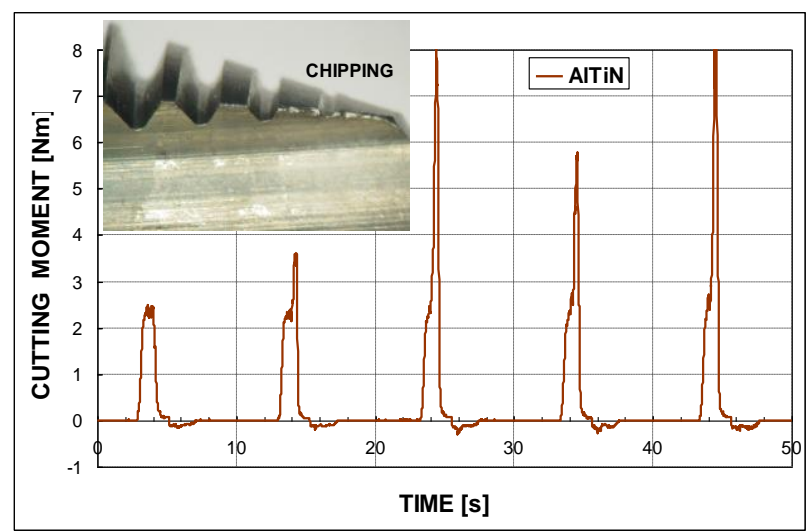

Fig.6 A time series of torque for HSSE+AlTiN, confirming a slightly better cutting performance in the austenitic steel

Slightly better results were achieved with the TiN coatings, but due to severe shearing loading this coating was not able to stand such cutting conditions for a longer time of cutting - Fig. 5. Statistically significant improvement of tool life $(\mathrm{p}=0.05)$ was reached with the AlTiN coating, but a chipping with built-up-edge was observed. The taps were able to substitute the missing cutting material with hardened machined material, but not for a long time and quality of the machined surface was not satisfactory. 
The best results were found with CrAlN coatings Fig. 7a,b. A smooth, stabilized tapping with a good chip formation and acceptable quality of the holes was found.

\section{CONCLUSIONS}

The PVD CrAlN coatings can be recommended for an effective tapping of the austenitic stainless steel. The accuracy of IT10-11, roughness $\mathrm{Ra} \leq 3.2 \mu \mathrm{m}$ and tool life for production of 40-45 holes with a stabilized tapping and torque can be expected. The uncoated HSSE and TiN coated taps exhibited a catastrophic failure after a few passes and similar poor results (12-14 threads) for AlTiN coating were observed and measured. All threads made with CrAlN coatings fullfilled the expected quality (design and dimensional criteria) apart of the last holes. The research will continue with TiAlN coatings, use of inner cooling and application on nano-structured TiAlSiN materials.
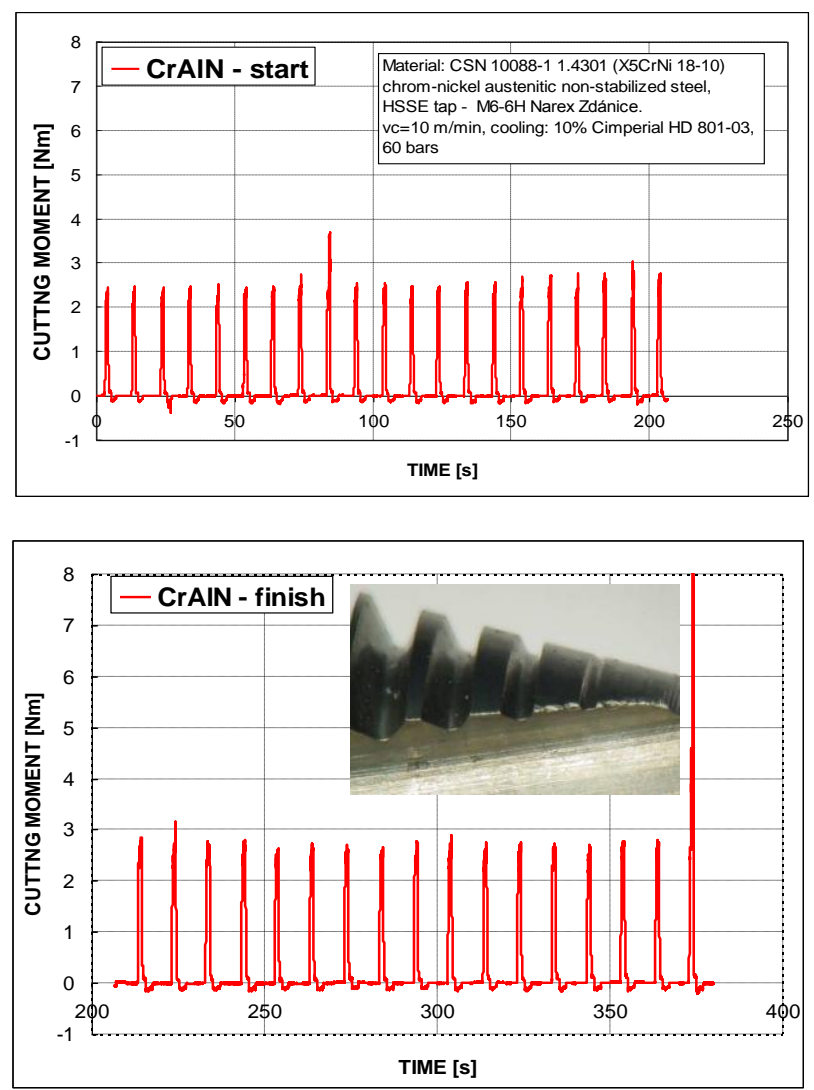

Fig.7.a,b Stabilised and safe tapping operations in the whole tool life with CrAlN coating

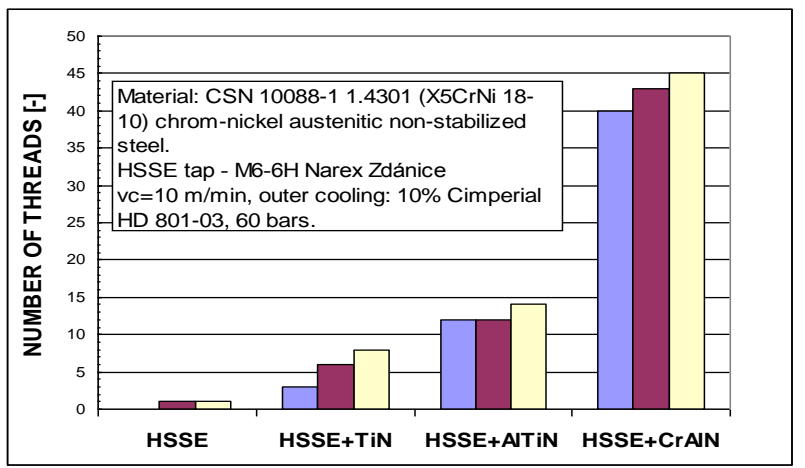

Fig.8. Cutting performance of all tested taps

\section{ACKNOWLEDGEMENT}

This research work was supported by the BUT, Faculty of Mechanical Engineering, Brno, Specific research 2011, with the grant "Reseach of advanced CNC methods for perspective applications", FSI-S-1128, ID 1438.

\section{REFERENCES}

[1] Piska, M., Slany, M.(2011). On the Reaming of Austenitic Steels with Coated Cermets. Annals of DAAAM for 2011 \& Proceedings of the 22th International DAAAM Symposium in Viena, pp.01170118, ISBN 978-3-901509-83-4

[2] Slany, M., Polzer, A. \& Piska, M. (2011) On the effective reaming of austenitic steels On the effective reaming of austenitic steels with cermet reamers and flood cooling. In: Proceedings of the SPS 11 The 4th International Swedish Production Symposium, The Swedish Production Academy, pp.228-234, Lund

[3] Veprek S. et al (2003). Limits to the strength of super and ultrahard nanocomposite coatings. J. Vac. Sci. Technol. A, Vol. 21, No. 3, , pp. 532-545

[4] Veprek S. et al. (2004) Mater. Sci. Eng., A 366202

[5] Prochazka J., Karvankova, P. Veprek-Heijman M.G.J. \& Veprek S. (2004). Conditions required for achieving superhardness of $\geq 45$ GPa in nc-TiN/a-Si3N4 nanocomposites. Materials Science and Engineering. A 384, pp. 102-116

[6] Rosén J., Larsson K. \& Schneider J.M. (2005) Journal of Physics: Condensed Matter 17 L13

[7] Rosén J., Widenkvist E., Larsson K., Kreissig U., Mráz S., Martinez C., Music D. \& Schneider J.M. (2006) Appl. Phys. Lett. 88. 191905-1

[8] Cselle T. \& Holubar P. (2003) Driving forces of today's manufacturing technology. p. Milling III. pp. 33-60, Brno (2003), ISBN 80-214-2436-2

[9] Zhao L., Munroe, P., Zhong-tao J., Zhao X., Xue J., Zhi-feng Z., Z., Jianga, J., Fanga F. \& Xieg Z.(2012). Designing superhard, self-toughening CrAlN coatings through grain boundary engineering. Acta Materialia Volume 60, Issue 16, September 2012, pp. 5735-5744

[10]Humar, A., Piska, M. (2004) Modern cutting tools and cutting materials. MM Prumyslove spektrum, Vol.2004, No. Special IX, pp. 112. ISSN 1212-2572

[11]Harish, C., Barshilia, N. Selvakumar, B. Deepthi \& Rajam, K.S. A comparative study of reactive direct current magnetron sputtered CrAlN and $\mathrm{CrN}$ coatings. Surface and Coatings Technology Volume 201, Issue 6, 4 December 2006, pp. 2193-2201

[12] Veprek, S., Veprek-Heijman, M.G.J., Jilek, M., Piska, M. Zeng, X. , Bergmaier \& A., Fang, Q. F. (2011): Oxygen Impurities in Ti-Si$\mathrm{N}$ and Related Systems are Hindering the Phase Segregation, Formation of Stable Nanostructure and Degrading the Cutting Performance of Tools Coated with the Nanocomposites, 20th International Symposium on Plasma Chemistry http://ispc20.plasmainstitute.org/, pp.54-57, ISBN 9241562676, (2011), A.J. Drexel Plasma Institute

[13] Veprek, S., Veprek-Heijman, M.J.G., Holubář, P., Cselle, T., Galassi, I. \& Píška, M. (2011) Applications of Hard and Superhard Nanocomposite Coatings on Tools for Machining, Forming and Stamping - A Guide for SMEs, 3/2011; VINF (The Virtual Institute of Nano Films)

[14] Piska, M., Polzer, A., Cihlarova, P. \& Stankova, D.(2009) On the Structural Integrity of the nano-PVD Coatings Applied On Cutting Tools, Damage and Fracture Mechanics Failure Analysis of Engineering Materials and Structures, pp.195-204, ISBN 978-90481-2668-2, Springer

[15] Shaw M.C. (2005) Metal Cutting Principles. Oxford University Press, 2nd ed., Oxford, pp. 651, ISBN 0-19-514206-3

[16]ISO 3002-4 (Basic Quantities in Cutting and Grinding -Part 4: Forces, energy, power) 